\title{
A THREE STEP PHOTOCHEMICAL REACTION SCHEME FOR DECOMPOSITION OF WATER
}

\author{
K. TENNAKONE, S. PUNCHIHEWA AND U.S. KETIPEARACHCHI \\ Institute of Fundamental Studies, Hantana, Kandy.
}

$\begin{array}{ll}\text { (Date of receipt } & : \text { 09 December 1991) } \\ \text { (Date of acceptance } & : \text { 28 September 1992) }\end{array}$

\section{INTRODUCTION}

The development of a practical system for decomposition of water into hydrogen and oxygen using sunlight is one of the most desired inventions. Although a great deal of experimentation ${ }^{1-9}$ has been carried out on this subject during the past decade, practically viable systems are yet unavailable. Chemical reactions based on homogeneous or heterogeneous photocatalysts capable of decomposing water are documented. ${ }^{1-9}$ However, the quantum and energy conversion efficiencies are not sufficient for commercial utilization. It is likely that new ideas are necessary for devising methods of photodecomposition of water. One of the most promising methods could be to adopt a series of light driven reactions where water is decomposed via a number of intermediate reactions. Instead of one step photodecomposition, a multi-step process has two distinct advantages. (1) Utilization of several photons for decomposition of one molecule of water, thereby making less energetic photons sensitive. (2) Back-reactions (i.e., recombination of hydrogen and oxygen in the active intermediate forms) are more easily suppressed in a multi-step process. In fact the most successful energy storing light reaction viz. photosynthesis, operates in this manner. The green plant photosynthetic apparatus consists of a two photosystems linked by a series of redox carriers. Earlier we have discussed several model systems for decomposition of water based on two photosystems. ${ }^{10-12}$ In this work, we describe a three step process as a model system for photodecomposition of water.

\section{METHODS AND MATERIALS}

Copper (II) chloride, silver nitrate, sodium choloride, metallic copper (Aldrich) and hydrochloric acid (BDH) were used as the starting materials. Copper (I) chloride was prepared by boiling metallic copper with a solution of copper (II) chloride in dilute hydrochloric acid avoiding oxygen contamination. Silver chloride was prepared by double decomposition of silver nitrate and sodium chloride in aqueous solution and separation and washing without exposure to light. All photolysis experiments were conducted in a thermostatted $\left(26^{\circ} \mathrm{C}\right)$ photochemical reactor (Applied photophysics) 
volume $300 \mathrm{ml}$ and prior to irradiation solutions were purged with nitrogen (99.999\%). The light source used was a $400 \mathrm{~W}$ medium pressure mercury lamp. A low pressure lamp (16W) was used to estimate the quantum yields and the photon flux was counted by ferrioxalate actinometry. Evolved gases were determined volumetrically at atmospheric pressure by gas chromatography (Shimadzu GC-9A gas chromatograph, column molecular sieve 5A, carrier gas Ar).

\section{RESULTS AND DISCUSSION}

The three steps are given below:

\section{Step 1}

A solution of copper (I) chloride in dilute hydrochloric acid liberates hydrogen upon UV irradiation with oxidation of copper (I) chloride to the copper (II) chloride [13], i.e.,

$$
\mathrm{CuCl}+\mathrm{HCl} \longrightarrow \mathrm{h}_{1} \mathrm{CuCl}_{2}+1_{2} \mathrm{H}_{2}
$$

Step 2

The irradiation of a suspension of particles of metallic silver in aqueous copper (II) chloride generates copper (I) chloride and silver chloride, ie.,

$$
\mathrm{CuCl}_{2}+\mathrm{Ag} \stackrel{\mathrm{h} v_{2}}{\longrightarrow} \mathrm{AgCl}+\mathrm{CuCl}
$$

Step 3

An aqueous suspension of silver chloride when irradiated liberates oxygen, i.e.,

$$
\mathrm{AgCl}+\sqrt{2}_{2} \mathrm{H}_{2} \mathrm{O} \stackrel{\mathrm{h} v_{3}}{\longrightarrow} \mathrm{Ag}+\mathrm{HCl}+\mathrm{V}_{4} \mathrm{O}_{2}
$$

The sum of reactions (1), (2) and (3) is

$$
\mathrm{V}_{2} \mathrm{H}_{2} \mathrm{O} \longrightarrow \sqrt{2} \mathrm{H}_{2}+\mathrm{V}_{4} \mathrm{O}_{2} \text { and all them can be driven by light. }
$$

Figure 1 illustrates production of hydrogen upon irradiation of a $\left(0.20 \mathrm{~mol} \mathrm{dm}^{-3}\right)$ solutionof $\mathrm{CuCl}$ containing $0.25 \mathrm{~mol} \mathrm{dm}^{-3}$ of $\mathrm{HCl}$. After several hours of photolysis, the solution turns pale green owing to formation of copper (II) chloride. The initial quantum yield of $\mathrm{H}_{2}$ production at $250 \mathrm{~nm}$ is $\sim 63 \%$. 


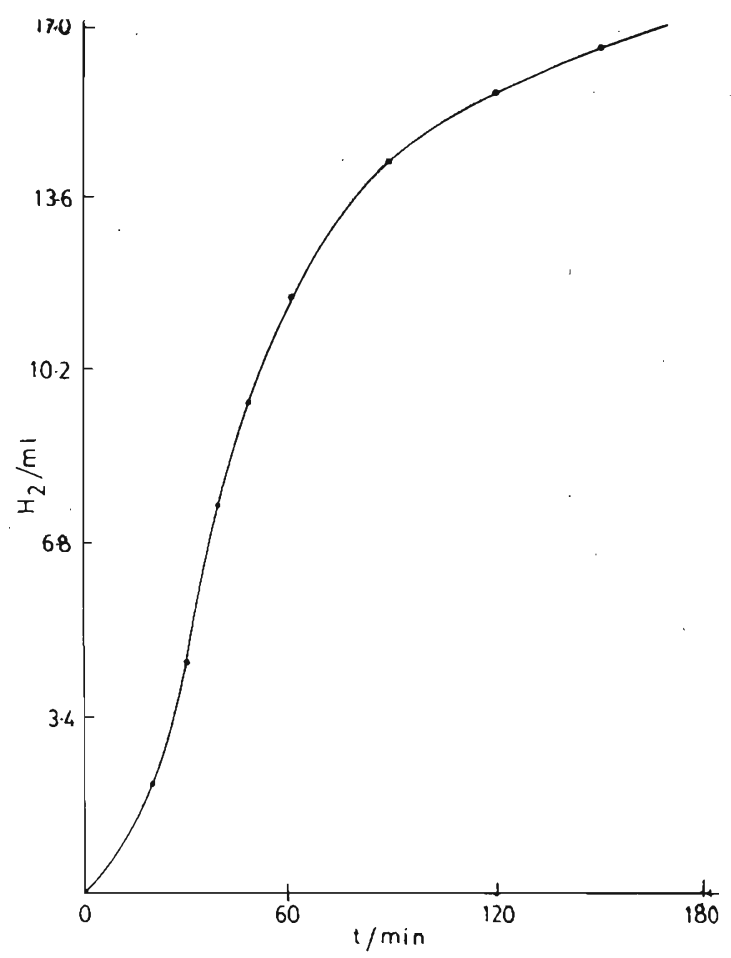

Figure 1: Hydrogen photogeneration from a $0.20 \mathrm{M}$ solution of $\mathrm{CuCl}$ in dilute $\mathrm{HCl}(0.25 \mathrm{M})$.

A solution of copper(II) chloride when irradiated liberates detectable quantities of both hydrogen and oxygen via the following reactions (Figure 2).

$$
\begin{aligned}
& \mathrm{CuCl}_{2}+v_{2} \mathrm{H}_{2} \mathrm{O} \stackrel{\mathrm{h} v}{\longrightarrow} \mathrm{CuCl}+v_{4} \mathrm{O}_{2}+\mathrm{HCl} \\
& \mathrm{CuCl}+\mathrm{HCl} \stackrel{\mathrm{h} v}{\longrightarrow} \mathrm{CuCl}_{2}+v_{2} \mathrm{H}_{2}
\end{aligned}
$$

In the presence of silver particles, the rates of hydrogen and oxygen evolution is increased (Figure $2 \& 3$ ) as a result of enhanced formation of $\mathrm{CuCl}$ via (2) and decomposition of $\mathrm{AgCl}$ via (3). The reaction (2) also occurs thermally: when silver dust is heated with a solution of copper (II) chloride, easily detectable quantities of copper (I) chloride are formed. We have found that, the rate of formation of copper (I) chloride in this reaction at $90^{\circ} \mathrm{C}$ is increased by UV irradiation of the solution as an increase of temperature decreases ${ }^{13}$ the photodecomposition of $\mathrm{CuCl}$ in $\mathrm{HCl}$ by the reaction 1 . 


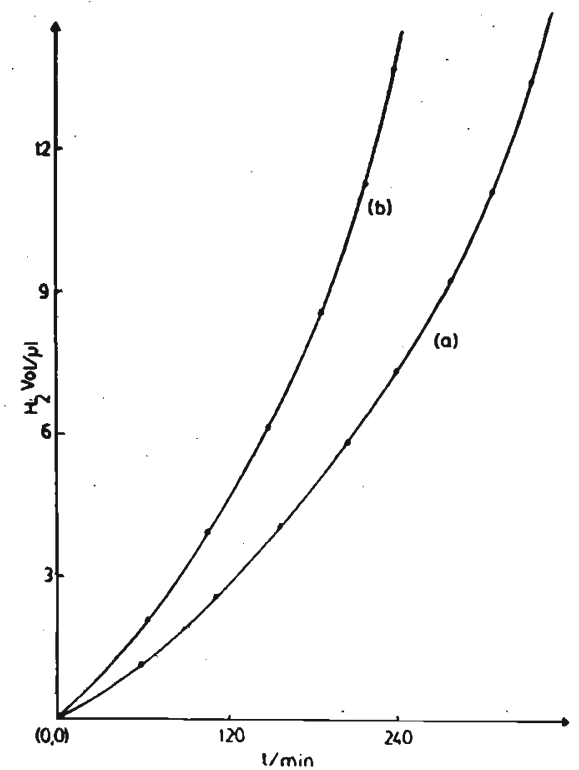

Figure 2: Hydrogen photogeneration (the plot of volume of gas vs time) during photolysis of (a) $0.20 \mathrm{M}$ solution $\mathrm{CuCl}_{2}$ containing $\mathrm{HCl}(0.25 \mathrm{M})$ (b) $0.20 \mathrm{M}$ solution of $\mathrm{CuCl}_{2}$ containing $\mathrm{HCl}(0.25 \mathrm{M})$ in the presence of $5 \mathrm{mg}$ of silver dust.

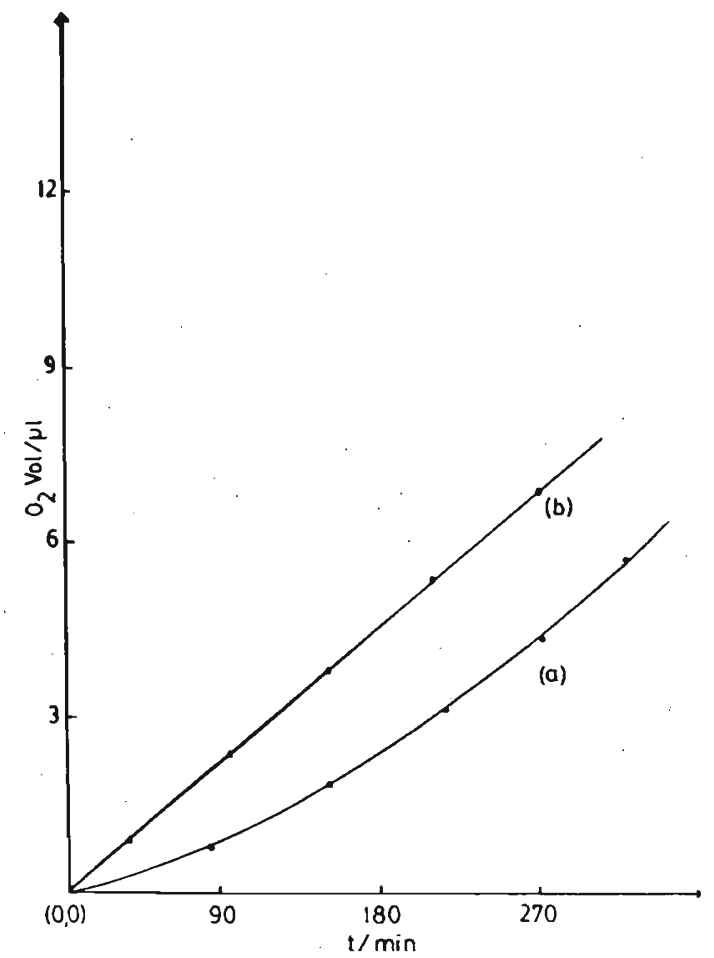

Figure 3: (a) Oxygen photogeneration during photolysis of a $0.20 \mathrm{M}$ solution $(0.25 \mathrm{M}$ in $\mathrm{HCl})$.

(b) Oxygen photogeneration from the same solution in the presence of $5 \mathrm{mg}$ of silver dust. 
Figure 4 illustrates oxygen evolution in the photodecomposition of an aqueous suspension of silver chloride. The photodecomposition of silver chloride depends on its semiconductor property, i.e. the photogenerated electrons and holes participate in the following reaction, i.e.,

$$
\begin{aligned}
& \mathrm{V}_{2} \mathrm{H}_{2} \mathrm{O}+\mathrm{h}^{+} \longrightarrow \mathrm{H}^{+}+\sqrt{4}_{4} \mathrm{O}_{2} \\
& \text { Valence band } \mathrm{AgCl}
\end{aligned}
$$

$$
\mathrm{AgCl}+\mathrm{H}^{+}+\mathrm{e}_{\text {Conduction band } \mathrm{AgCl}} \longrightarrow \mathrm{HCl}+\mathrm{Ag}
$$

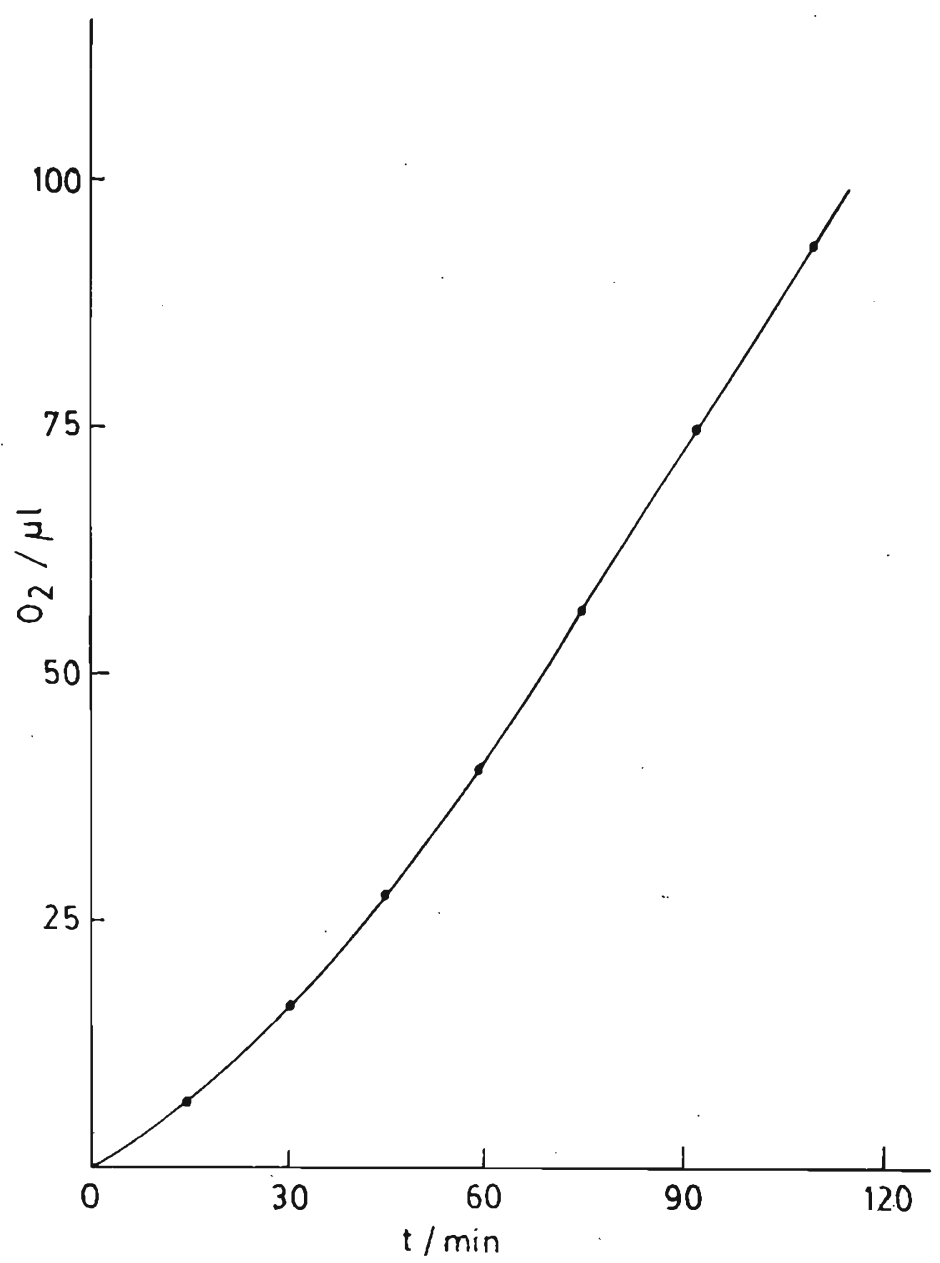

Figure 4: Oxygen evolution during photolysis of $50 \mathrm{mg} \mathrm{AgCl}$ in $200 \mathrm{ml}$ of water. 
As a consequence of (1), (2) and (3), on prolonged photolysis, a solution of $\mathrm{CuCl}_{2}$ containing $\mathrm{Ag}$ or $\mathrm{AgCl}$ generates both oxygen and hydrogen. If the reaction (2) is carried out thermally, $\mathrm{AgCl}$ can be separated from the $\mathrm{CuCl}$ containing solution and the reactions (1) and (3) carried out independently. Reactions (1) and (2) depend on charge transfer absorption in the complexes of $\mathrm{CuCl}$ and $\mathrm{CuCl}_{2}$ with $\mathrm{HCl}$ (i.e. trichlorocuprate (I) and (II) ions) with absorption peaks near 275 and $250 \mathrm{~nm}$ respectively. Light of wavelength less than band gap radiation of $\mathrm{AgCl}(\sim 390 \mathrm{~nm})$ is responsible for reaction (3). Although the above reaction scheme is not practical at the moment, it gives much insight into the possibility of multi-step reactions for decomposing water into hydrogen and oxygen.

\section{References}

1. Gratzel M. (1981). Accounts of Chemical Research 14: 376.

2. Harriman A. \& West M.E. (Eds.) (1983). Photogeneration of Hydrogen, Academic Press, London.

3. Bockris J.O'M., Dandapani B., Cocke D. \& Ghoroghechian J. (1985). International Journal of Hydrogen Energy 10: 179.

4. Gratzel M. (Ed.) (1983). Energy Resources through Photochemistry and Catalysis, Academic Press, New York.

5. Willner I. \& Willner B.S. (1988). International Joumal of Hydrogen Energy 15: 593.

6. Bard A.J. (1980). Science 207: 139.

7. Lehn J.M., Sauvage S.P. \& Ziesel R. (1980). Nouveav Journal De Chimie 4: 623.

8. Honda K. \& Frank A.J. (1984). Journal of Physical Chemistry 88: 5577.

9. Blondeel G., Harriman A. \& Williams D. (1983). Solar Energy 9: 217.

10. Tennakone K. \& Wickramanayake S. (1986). Joumal of the Chemical Society, Faraday Transactions 82:1475.

11. Tennakone K. and Pushpa S. (1985). Journal of the Chemical Society, Chemical Communications 1436.

12. Tennakone K. (1987). Intemational Journal of Hydrogen Energy 12: 79.

13. Davis D.D., Stevenson K.L. \& Davis C.R. (1978). Journal of the American Chemical Society 100: 5344. 